\title{
Las cosas naturales y las cosas no naturales; las fronteras de lo hereditario en el siglo XVIII
}

\author{
CARLOS LÓPEZ BELTRÁN \\ Instituto de Investigaciones Filosóficas \\ Universidad Nacional Autónoma de México \\ lbeltran@servidor.unam.mx
}

\begin{abstract}
Resumen: Este artículo intenta delimitar el espacio conceptual en el que se concibió la transmisión hereditaria de peculiaridades físicas y morales durante el siglo XVIII europeo. El terreno de lo hereditario en ese periodo estaba vinculado a la comunicación, de padres a hijos, de componentes accidentales del cuerpo, que podían de algún modo transmitirse usando las vías de la reproducción biológica. Al mismo tiempo, todo lo que tenía que ver con la reproducción de los rasgos esenciales del cuerpo estaba, conceptualmente, fuera del alcance de la noción de lo hereditario. Las diferentes teorías dieciochescas de la reproducción asumieron esta dicotomía, que representaba una frontera interna para la noción de herencia. El predominio en el mismo periodo del esquema galénico de las cosas naturales y las cosas no naturales permite una exploración complementaria de la frontera externa para la transmisión hereditaria. La posibilidad de que el cuerpo (la constitución, el temperamento) pudiera transformarse por influencias externas, y que estos cambios en ciertas circunstancias pudieran a su vez comunicarse a la descendencia, definió la negociación de esta segunda frontera.
\end{abstract}

Palabras clave: herencia, galenismo, biología e Ilustración

La transmisión hereditaria de los rasgos corporales (físicos) y conductuales (morales) de los padres a los hijos se volvió un objeto de teorización científica independiente apenas a mediados del siglo XIX. Sólo entonces quedó claro que las cuestiones en torno a la estabilidad de las especies y la cuestión acerca de las similitudes contingentes responsables de los parecidos familiares se entretejían ceñidamente, y que aquéllas y ésta se podían explicar de una manera unificada. La preocupación teórica por cómo se lleva a cabo dicha transmisión se convirtió a partir de ese momento en un tema fundamental para los biólogos. ${ }^{1}$ Hasta entonces, lo relacionado con la conservación del tipo en una línea genealógica se consideró un asunto fundamental para el conocimiento de la vida, mientras que la fenomenología de la comunicación hereditaria de los rasgos accidentales dentro de los linajes se entendía como algo de importancia secundaria. La excepción la encontramos en unos cuantos contextos locales, entre los hibridólogos, y en particular entre algunos fisiólogos y médicos cuyos intereses enfocaban

${ }^{1}$ López-Beltrán 1992, 1994; Churchill 1987. 
su atención hacia la posibilidad de la transmisión hereditaria de rasgos de ascendientes a descendientes en una línea genealógica.

En otro texto he sostenido que la adopción después del decenio de 1830 de la palabra herencia, en su acepción naturalista, primero en francés y luego en otras lenguas europeas, marca el viraje decisivo, cuando el cambio del uso adjetival (en el cual siempre debía haber una peculiaridad hereditaria) al uso de un sustantivo (Hérédité) revela una conciencia cada vez mayor de la existencia de una vía causal a la que se podían atribuir las regularidades (y las irregularidades) observadas. ${ }^{2}$ También he sostenido que, antes de ese periodo, había un conjunto de fenómenos aceptados que, entre los médicos y los naturalistas, se asociaban al uso del adjetivo "hereditario", y que fueron evaluados y explicados (habitualmente minimizándolos) de distintas formas en las distintas épocas.

Desde la Antigüedad hasta la era moderna puede seguirse una tradición más o menos discreta que consistía en prestar atención y acumular descripciones, e intentar explicar cómo se comunican los accidentes hereditarios a través de linajes y llegan a ser la causa de caracteres físicos y morales que perviven en ellos. Algunos ejemplos famosos son la explicación mixta (cultural-hereditaria) que Aristóteles ofreció en el caso de los dolicocéfalos ("cabezas alargadas"); ${ }^{3}$ la compleja explicación (dinámica) fisiológica que el mismo Aristóteles dio del parecido de los hijos con ambos padres; ${ }^{4}$ el recurso de los hipocráticos y los galénicos a los modelos de reproducción de doble simiente a fin de dar cuenta del parecido en general; ${ }^{5}$ las concepciones astrológicas medievales de las peculiaridades distintivas de los hijos; la influyente teoría dualista de Paracelso, en la que la imaginación podía inducir tanto el parecido como la monstruosidad; ${ }^{6}$ los intentos médicos (después del Renacimiento) por explicar la transmisión hereditaria de las enfermedades y monstruosidades dentro de líneas familiares según distintos marcos teóricos. ${ }^{7}$

En 1775, Immanuel Kant propuso una distinción analítica que puede ser útil en nuestras descripciones. Sugirió que las variaciones hereditarias deberían denominarse "similitudes" si "coinciden con sus derivaciones" (los hijos "salen a" uno o a ambos padres, o a algún ancestro), y "degeneraciones" (tomando aquí la noción de Buffon) si se alejan de la norma de tal modo "que la formación original no pueda ser restaurada". ${ }^{8}$ A mediados del siglo XVIII se solía incluir un conjunto de fenómenos más o menos estables

\footnotetext{
2 López-Beltrán 1992, 1994.

${ }^{3}$ Véase Glacken 1967.

${ }^{4}$ Véase Coles 1995.

${ }^{5}$ Véanse Boylan 1984, 1986; Jacob 1970; Lloyd 1983; Coles 1995.

${ }^{6}$ Véanse, por ejemplo, Glacken 1967; Rádl 1930.

${ }^{7}$ Véase López-Beltrán 1992.

${ }^{8}$ Véase Kant 1775, en Chukwudi 1997, p. 20.
} 
en esta categoría extraña de lo hereditario. Fuesen similitudes o degeneraciones, el hecho de que hubiese peculiaridades no esenciales en ciertos rasgos que no todos los miembros de una especie o linaje compartían, y que lograsen ser re-producidas con cierta fidelidad en los descendientes se consideró un atolladero para los sistemas descriptivos y explicativos tanto en la historia natural como en la fisiología. Se puede decir que, durante los siglos XVII y XVIII, se forjó una relación especial entre tal conjunto de fenómenos hereditarios y los modelos teóricos de la generación que por entonces se discutían con vehemencia. El parecido con ambos progenitores, las peculiaridades mixtas de las mulas, los orígenes y la transmisión de la monstruosidad, etc., se convirtieron en un campo de evidencias determinante para la discusión.

Lo hereditario fue así, durante las décadas medias del siglo XVIII, un conjunto de fenómenos que unos y otros debían "salvar" para consolidar sus teorías de la generación. El diccionario Chambers (1738), por ejemplo, en su entrada relativa a "la generación", menciona que Sir John Floyer "inaugura una dificultad que parece presionar igualmente en contra de ambos sistemas (ovismo y animaculismo), tomados por separado"; se trata del hecho de que las mulas tengan algunas de las características del caballo y del asno, y que, para (explicar) la determinación del origen del feto, los defensores de ambos sistemas elijan caprichosamente como caracteres importantes los que apoyan su punto de vista, y que califiquen de secundarios a los caracteres que comunica el sexo opuesto. ${ }^{9}$ En 1750 , cuando Diderot preparaba los élemens de physiologie, atribuyó un peso especial a los hechos hereditarios para la evaluación de los diversos sistemas teóricos sobre la generación que entonces estaban en competencia. La dificultad que las posturas preformacionistas tienen al abordar las "enfermedades hereditarias; el parecido con los padres; las mulas y los mulos que engendran" fue particularmente destacada por él en esas notas. ${ }^{10}$ $\mathrm{Al}$ comienzo de sus Considérations sur les corps organisés, Charles Bonnet planteó algunos de los retos que su posición preformacionista tenía que enfrentar:

Si los gérmenes están contenidos originalmente en los ovarios de la hembra, y si la materia seminal no es más que una especie de fluido nutriente, cuyo destino es convertirse en el principio del desarrollo, ¿de dónde salen los diversos rasgos del parecido de los hijos con quienes los trajeron al mundo? ¿Por qué existen los monstruos? ¿Cómo se forman las mulas ${ }^{11}$

\footnotetext{
${ }^{9}$ Véase "Generation", en Chambers Dictionary, 1738, vol. I.

10 Véase "Génération", cap. XXIV de Diderot 1964, pp. 182-185.

${ }^{11}$ Bonnet, Considérations 1985 (1778) p. 31.
} 
tarias. ${ }^{19}$ Lo que Louis se empeñaba en establecer era la imposibilidad en ese caso de que algún rasgo anatómico peculiar ("sólido") de los padres pudiera servir de origen a un rasgo similar en los hijos. Cualquier similitud tiene que obedecer a causas externas comunes; lo que es singular, individual, es que cada nuevo ser adquiere peculiaridades. Para él, la generación es algo completamente independiente de ello. Acerca de la posibilidad de las enfermedades hereditarias, Louis escribe: "los desórdenes de la economía animal deben ser adquiridos específicamente por cada ser humano: todas las enfermedades serán individuales, porque deben ser posteriores a la formación de los gérmenes que no han recibido ninguna alteración en su principio". ${ }^{20}$

En el siglo XVIII, las fronteras causales de lo hereditario se trazaron de una manera muy diferente de como nos hemos acostumbrado a hacerlo después de que se instauró, a finales del siglo XIX, la distinción naturalezacrianza (nature-nurture). En el caso humano, la explicación de las peculiaridades corporales del individuo seguía estrechamente vinculada a nociones médicas complejas y abiertas, como la constitución, el temperamento, etc., en la que una interacción entre los elementos externos e internos era la causante de los rasgos idiosincrásicos de la forma y la función (o disfunción).

Las restricciones que tanto Haller como Louis (en sus diferentes proyectos) imponen a la idea de transmisión hereditaria de las peculiaridades del individuo de algún modo estrangulan la posibilidad de tal transmisión cerrando la pinza entre dos dominios causalmente independientes: lo interno vinculado a la generación del germen (es decir, su primera formación), y las influencias externas, circunstanciales, sobre el cuerpo. Entre otras cosas, lo que sus argumentos obstaculizaban era la posibilidad de que los efectos de las influencias externas (el clima, los alimentos, etc.) se integrasen de algún modo en los linajes y, a la larga, se incorporasen a ellos de una manera no accidental. Para tales autores, no es concebible la existencia de un modo en el que las variaciones accidentales (de cualquier tipo) puedan ser heredadas de padres a hijos con alguna regularidad. Si, por ejemplo, las similitudes familiares fuesen causadas por una transmisión de rasgos peculiares de padres a hijos por vía de la generación, de todos modos éstas tendrían poca importancia. Para ellos, lo hereditario pertenecía, si a algún sitio, a la esfera de lo anecdótico.

Un modo particularmente iluminador y sorprendente de acercarnos al marco conceptual en el cual las cuestiones hereditarias se articulaban durante

\footnotetext{
${ }^{19}$ Véase un análisis de esta disertación en López-Beltrán 1994.

${ }^{20}$ Louis 1749, p. 35.
} 
la especulación fisiológica, ${ }^{15}$ en contraste con la frontera interior definida por la disección y la microscopía. Reunir casos convincentes de transmisión hereditaria de una amplia gama de rasgos diferentes, y la cancelación progresiva de cursos causales alternativos para dar cuenta de ellos, ${ }^{16}$ fueron así temas centrales de los debates del siglo XVIII en torno a la generación. Algunos aspectos importantes del muy sofisticado ovismo de Bonnet (en el que adopta estratégicamente varios aspectos de teorías de doble simiente rivales) fueron, sin duda, consecuencia de las presiones que los hechos hereditarios plantearon al preformacionismo.

Con todo, lo hereditario no constituyó durante el siglo XVIII un conjunto de hechos incuestionable ni un dominio de referencia aceptado por todos. La transmisión hereditaria como hecho aún podía ser puesta en duda. Se trató de un dominio inestable, plagado de irregularidades. Al revisar la teoría de la generación de Buffon, Haller consideró importante llegar hasta el extremo de negar su realidad. "Prefiero simplemente negar a Monsieur Buffon que los hijos se parezcan a los padres [...], los hijos ya no son imágenes de sus padres" ("y el resto del edificio caerá por sí solo"). Haller basa su creencia en el número mayor de excepciones que de casos positivos; en especial, en el hecho de que internamente (anatómicamente) no hay nunca un patrón de nervios o venas idéntico compartido entre padres e hijos. ${ }^{17}$ Comentando tal negación extrema de Haller, Duchesneau escribe que ésta ilustra con especial claridad el carácter "individual" de la generación a los ojos de los sabios de la primera mitad del siglo XVIII. ${ }^{18}$ Esto habría que matizarlo. La generación más que individual era considerada, por una mayoría, responsabilidad de leyes naturales (o divinas) que producían a cada individuo por separado; esto hacía que los vínculos genealógicos se consideraran irrelevantes para lo fundamental. Ahora bien, lo que permanecía en disputa era si la generación era responsable de todos los rasgos, generales y particulares, del individuo, o sólo de los primeros. El aceptar esta última opción dejaba abierta la posibilidad de que justamente todo lo individual, lo accidental, fuese objeto de las intervenciones tanto del medio exterior como de la influencia ancestral (lo hereditario).

En 1747, el médico francés Antoine Louis expresó una negación similar a la de Haller en una influyente discusión sobre las enfermedades heredi-

\footnotetext{
${ }^{15} \mathrm{Al}$ examinar, por ejemplo, los cambiantes conjuntos de condiciones en los cuales ocurre la transmisión hereditaria, cuándo y con qué regularidad se conservan algunos rasgos en un linaje.

${ }^{16}$ Por ejemplo, desembarazarse de ellos atribuyendo su ocurrencia a la oportunidad, o llamándolos irrelevantes.

${ }^{17}$ Haller 1752, (Reflections...), p. 32. La traducción al inglés de Phillip Sloan (Reflections on the Theory of Generation of Mr. Buffon, p. 318) insiste en que las similitudes que niega Haller son replicaciones "exactas", un problema importante que se debería analizar consultando el texto en alemán.

${ }^{18}$ Duchesneau 1982, nota 132, p. 539.
} 
tarias. ${ }^{19}$ Lo que Louis se empeñaba en establecer era la imposibilidad en ese caso de que algún rasgo anatómico peculiar ("sólido") de los padres pudiera servir de origen a un rasgo similar en los hijos. Cualquier similitud tiene que obedecer a causas externas comunes; lo que es singular, individual, es que cada nuevo ser adquiere peculiaridades. Para él, la generación es algo completamente independiente de ello. Acerca de la posibilidad de las enfermedades hereditarias, Louis escribe: "los desórdenes de la economía animal deben ser adquiridos específicamente por cada ser humano: todas las enfermedades serán individuales, porque deben ser posteriores a la formación de los gérmenes que no han recibido ninguna alteración en su principio". ${ }^{20}$

En el siglo XVIII, las fronteras causales de lo hereditario se trazaron de una manera muy diferente de como nos hemos acostumbrado a hacerlo después de que se instauró, a finales del siglo XIX, la distinción naturalezacrianza (nature-nurture). En el caso humano, la explicación de las peculiaridades corporales del individuo seguía estrechamente vinculada a nociones médicas complejas y abiertas, como la constitución, el temperamento, etc., en la que una interacción entre los elementos externos e internos era la causante de los rasgos idiosincrásicos de la forma y la función (o disfunción).

Las restricciones que tanto Haller como Louis (en sus diferentes proyectos) imponen a la idea de transmisión hereditaria de las peculiaridades del individuo de algún modo estrangulan la posibilidad de tal transmisión cerrando la pinza entre dos dominios causalmente independientes: lo interno vinculado a la generación del germen (es decir, su primera formación), y las influencias externas, circunstanciales, sobre el cuerpo. Entre otras cosas, lo que sus argumentos obstaculizaban era la posibilidad de que los efectos de las influencias externas (el clima, los alimentos, etc.) se integrasen de algún modo en los linajes y, a la larga, se incorporasen a ellos de una manera no accidental. Para tales autores, no es concebible la existencia de un modo en el que las variaciones accidentales (de cualquier tipo) puedan ser heredadas de padres a hijos con alguna regularidad. Si, por ejemplo, las similitudes familiares fuesen causadas por una transmisión de rasgos peculiares de padres a hijos por vía de la generación, de todos modos éstas tendrían poca importancia. Para ellos, lo hereditario pertenecía, si a algún sitio, a la esfera de lo anecdótico.

Un modo particularmente iluminador y sorprendente de acercarnos al marco conceptual en el cual las cuestiones hereditarias se articulaban durante

\footnotetext{
${ }^{19}$ Véase un análisis de esta disertación en López-Beltrán 1994.

${ }^{20}$ Louis 1749, p. 35.
} 
el siglo XVIII es la que ofrece la distinción galénica entre "las cosas naturales" y "las cosas no naturales". En la medicina del siglo XVIII, la frontera entre cuerpo y medio ambiente, entre fisiología y entorno (milieu), puede delimitarse usando estos conceptos. Arnulfe D'Aumont, en un artículo para la Encyclopédie, definió las (seis) cosas no naturales: "llamamos entonces no naturales (según Galeno ${ }^{21}$ ) a las cosas que no componen nuestra naturaleza ni nuestro ser, pero de las cuales la economía animal sufre grandes efectos, grandes cambios, grandes alteraciones". ${ }^{22}$

La lista de las seis cosas no naturales es de algún modo sorprendente para la mentalidad moderna: "el aire, los alimentos, el trabajo y el descanso, el sueño y la vigilia, las excreciones retenidas o evacuadas, y las pasiones del alma". ${ }^{23}$ Los galenistas contrastan estos factores externos con las llamadas "(siete) cosas naturales", y que por naturaleza son parte esencial de la constitución corporal del individuo: "los elementos, los temperamentos, las partes, los humores, los espíritus, las facultades y las acciones: son aquellas que contribuyen a formar lo físico de nuestro ser".

La coherencia y el poder explicativo y lógico de este marco conceptual han sido estudiados y discutidos en varios ensayos por William Coleman, quien afirma, entre otras cosas, que en el siglo XVIII

la doctrina de los no naturales ofrecía un marco de referencia conciso, flexible y ampliamente aceptado para articular las exigencias primordiales que las condiciones de existencia imponían a hombres y mujeres que intentaban seriamente conservar su bienestar físico [.. .]. Los no naturales se convirtieron en parte integral de un nuevo orden moral y en buena medida secular. ${ }^{24}$

Creo que también podemos hacer uso de dicho marco conceptual para concentrarnos en cómo se delineó en la época la frontera entre las determinaciones internas y externas de los rasgos corporales y la constitución, a fin de plantear el asunto de la permeabilidad y, en algún sentido, la fluidez entre las acciones internas (naturales) y las externas (no naturales).

La antigua idea del cuerpo como producto de una mezcla de humores (crasis, temperamento), sujeto a constantes y múltiples influencias humorales, desempeñó un papel importante en este tipo de temas; estas cuestiones se vincularon a la individualidad del temperamento y al posible papel explicativo que la geografía ("aires, aguas y lugares") y la genealogía (familia,

${ }^{21}$ Galeno fue el inspirador del concepto de seis cosas no naturales, aunque en realidad no lo acuñó. Basándose en unas cuantas sugerencias que dio acerca de qué influencias externas era importante verificar a fin de promover una vida saludable, sus seguidores terminaron estableciendo una estrecha lista de seis factores determinantes. Véanse estudios históricos del concepto en Niebyl 1971, Rather 1968, D’Aumont 1765 y Nutton 1993.

22 D'Aumont 1765.

23 Véanse Louis 1749, p. 18, y D’Aumont 1765.

${ }^{24}$ Coleman 1974, p. 406. Véase también Coleman 1984. 
tribu, nación) podían desempeñar respecto de él. Si tomamos de nueva cuenta el análisis de Antoine Louis como ejemplo de una postura radical, veremos que él insistía en la individualidad extrema del cuerpo:

El temperamento de los hijos que nacen de un mismo padre, y de una misma madre, es casi siempre diferente; algunos son biliosos [bilieux], otros sanguíneos [sanguins], algunos son alegres [guais], otros sosos [pésans]: estas diferencias de humor, de carácter y de inclinación entre hermanos y hermanas, son consecuencia de la diferencia de temperamentos; y ésta depende tal vez menos de la constitución primitiva o radical, que parece ser la misma entre todos los hijos, que de una disposición adquirida por la combinación infinitamente variada de todas las cosas exteriores. ${ }^{25}$

Entre las influencias externas que Louis menciona están el clima que había al nacer, el sufrimiento durante el nacimiento, la cantidad de sangre en los vasos al nacer, la calidad de la leche de la nodriza, la densidad del aire respirado durante las primeras horas, etc. ("no acabaríamos de hacer la enumeración"). Las primeras influencias externas tienen los efectos más duraderos en el temperamento del individuo. Las enfermedades futuras (o las predisposiciones a ellas) se suelen adquirir en etapas muy tempranas. Louis se mantuvo firme en que, pese a todo, estas adquisiciones (patológicas o no) no se transmitían a la siguiente generación.

(si la) diversidad de los temperamentos no es hereditaria, cómo podrían las enfermedades que son su consecuencia transmitirse a través de los padres. ${ }^{26}$

[...] las variaciones no deciden entonces nada en favor de la cuestión de las enfermedades hereditarias, ya que éstas no vienen de un principio interno y de disposiciones inherentes e inmutables; sino que dependen únicamente de las cosas no naturales que son todas exteriores. ${ }^{27}$

Como he mostrado en otro texto ${ }^{28}$ unos decenios después, la mayoría de los críticos de Louis centraron su ataque en su "increíble" argumento contra la realidad de la transmisión hereditaria, en lo que vieron como la falsa suposición de que los temperamentos son en definitiva individuales, secundarios y accidentales. Una proporción considerable de médicos creía que la posibilidad de transmitir peculiaridades corporales por la línea familiar era algo simplemente imposible de negar. En contraste con la actitud de Haller

${ }^{25}$ Louis 1749 , p. 35

${ }^{26}$ Ibid., p. 37.

${ }^{27}$ Ibid., pp. 74-75. Más adelante escribe: "Los hombres están sometidos a esta regla general como las plantas y los animales, su carácter y su temperamento dependen de una infinidad de cosas exteriores que pueden variar hasta el infinito: es una verdad aceptada en medicina."

${ }^{28}$ López-Beltrán 1994. 
y Louis, afirmaban que se debía conceder prioridad a los hechos sobre la teoría.

Para entender las diferencias sobre este tema entre los médicos del siglo XVIII, habría que considerar una importante división "teórica" entre ellos (una división que, hasta donde sé, no se ha discutido suficientemente): la que separó a los solidistas de los humoralistas. La de estos últimos es, desde luego, la tradición más antigua, y es la creadora del principal esquema conceptual de la medicina hipocrático-galénica. ${ }^{29}$ Su justificación de la unidad y diversidad de las propensiones humanas corporales y espirituales gira en torno al equilibrio de los constituyentes fluidos (humorales) y su relación con el ambiente. ${ }^{30}$ Como lo expresó Vivian Nutton "las ventajas de este esquema lógico pueden verse mejor en el desarrollo, dentro del marco del humoralismo, de la teoría de los seis no naturales". ${ }^{31}$ El solidismo es un producto médico del mecanicismo moderno; está vinculado a la búsqueda de causas mecánicas estructurales dentro del cuerpo. Posiciones teóricas como la iatromecánica y la fisiología de fibras expresan su principal planteamiento: la enfermedad y la normalidad deberán encontrarse en las propiedades físicas de la organización. Las lesiones (y no el mal temperamento) son la causa de las enfermedades.

Sobre el tema de la permeabilidad de la frontera entre cuerpo y ambiente, estas dos posiciones teóricas trabajaban sobre diferentes presupuestos. Si, mecanicistamente, se concede primacía causal (etiológica) a las partes sólidas (fibras, tejidos, órganos) sobre las porciones de fluidos en el cuerpo (como Louis arguye), ${ }^{32}$ entonces se vuelve mucho menos probable que presencias externas (aire, efluvios, aguas, alimentos, clima en general) puedan afectar irreversiblemente las propiedades corporales de un linaje; en especial, si el origen de los principales rasgos de los sólidos (organización) se considera preformado. Es decir, las partes sólidas de cada nuevo

\footnotetext{
${ }^{29}$ Sobre la historia de estas doctrinas médicas, véanse Portal 1808 y Adams 1814.

${ }^{30}$ Como Vivian Nutton lo define: "El humoralismo es un sistema de medicina que considera que la enfermedad es resultado de cierta alteración en el equilibrio natural de los humores, en el cuerpo como un todo o en alguna parte específica. Subraya la unidad del cuerpo y la fuerte interacción entre procesos mentales y físicos. Es a la vez altamente individualista, pues cada persona y cada parte corporal tiene su propia composición humoral natural (también conocida como crasis, mezcla, o temperamento), y universal, pues el margen de variación está limitado y se puede pensar que los mismos patrones patológicos (enfermedades) ocurren en muchos individuos. El equilibrio natural de la salud siempre es precario, ya que constantemente está sujeto a influencias potencialmente dañinas de la dieta, el estilo de vida y el ambiente." Nutton 1993, p. 281.

${ }^{31}$ Nutton 1993, p. 288.

${ }^{32}$ Louis escribe: "la acción de las fibras, más o menos fuerte y vigorosa, da forma y modifica de manera diferente los humores de nuestro cuerpo; estos humores se comportan dependiendo de su cantidad en los sólidos en los cuales están contenidos, y determinan de forma diversa las acciones: de ahí provienen las complexiones particulares que causan tanta diferencia entre los seres humanos, tanto en relación con las disposiciones del cuerpo como con los rasgos del espíritu". Louis 1749, pp. 37-37.
} 
ser, responsables últimas de sus funciones, no recibirán ninguna influencia regular, fisiológicamente normal, de las partes sólidas de sus ancestros; nada ocurre al formarse el nuevo ser que merezca el nombre de herencia. Por otro lado, si se concede la primacía a las mezclas humorales (y si se piensa que los sólidos son producto de una solidificación o condensación de humores después de la fecundación), entonces resulta concebible que al formarse el nuevo ser se altere el plan de su organización debido a las particularidades (las calidades) de los materiales provenientes de las simientes parentales. Al mismo tiempo se vuelve concebible que devenga relativamente "permanente" en el linaje cualquier influencia que pueda abrirse paso por el aire, el agua, la comida, etc., y cambie drásticamente el equilibrio humoral de una persona, y que con ello se altere su constitución física. Esto debido a que, a su vez, dicha alteración afectará los humores reproductivos de la siguiente generación, como el semen, la sangre, la leche. ${ }^{33}$

Así, en el contexto de los rasgos hereditarios (similitudes, degeneraciones), creo que la distinción entre cosas naturales y no naturales, y la concepción de sus interacciones, pueden ser esclarecedoras. Un recurso explicativo tradicional de la variación en las especies biológicas, en especial en el caso del ser humano, consiste en apelar a las influencias externas. La explicación climática (geográfica) es antigua. ${ }^{34}$ Durante el siglo XVIII, teóricos importantes como Arbuthnot, Falconer, Montesquieu, Buffon, etc., ${ }^{35}$ confirieron un papel central a la acción del sol, el aire, el agua, etc., en la explicación de la diversidad de la constitución corporal (y de las costumbres). Este origen externo de la diferencia a menudo se combinó con discusiones concernientes a las similitudes y las degeneraciones. A menudo, tanto la discusión empírica como la teórica tomaron como objeto lo que podría denominarse la "persistencia" (capacidad de permanecer en el linaje) de las alteraciones inducidas externamente. Los sistemas (o modelos) de la generación rivales se tuvieron que adaptar a los datos reunidos y a la opinión consensuada en torno al tema.

Es de interés notar que las concepciones de la transmisión hereditaria asociadas al vitalismo francés tendían a ponerse de parte de una concepción más permeable respecto del vínculo entre cuerpo y ambiente. Esta posición abierta, que vio en los equilibrios (complejos) entre elementos internos y externos del cuerpo el único enfoque realista convincente para la salud (y para la historia natural), dio cabida a la concepción posterior de un enfoque higienista de la salud, así como de un mejoramiento físico de la

\footnotetext{
${ }^{33}$ La capacidad que estamos dispuestos a conceder a un humor fue un tema de debate. Haller criticó severamente la disposición de los tibios humoralistas a aceptar que esos fluidos amorfos pudieran por sí mismos producir algún orden sensato.

${ }^{34} \mathrm{Su}$ locus classicus está en el hipocrático Airs, Waters, Places.

${ }^{35}$ Véase Glacken 1967.
} 
humanidad. Una diferencia crucial entre el hereditarismo francés y el británico en el curso del siglo XIX se debía exactamente a esta permeabilidad adoptada por los franceses. Como Coleman claramente lo mostró, la idea de las cosas no naturales fue el antecedente de los programas higienistas en los años posteriores al régimen napoleónico. Elizabeth Williams ha seguido de manera brillante la influencia del vitalismo en los acercamientos decimonónicos al vínculo entre cuerpo y ambiente por parte de los médicos franceses. ${ }^{36}$

Los humoralistas en su conjunto se inclinaron a lo que podríamos llamar una postura holista de los vínculos entre el cuerpo y el ambiente, y les pareció concebible que algún tipo de flujo (de caracteres externamente inducidos) pudiera viajar, por medios fisiológicos, en las líneas familiares y conformar un patrimonio corporal peculiar de familias, tribus y razas. Por otra parte, para los solidistas (à la Louis), dado que no podían imaginar ninguna ruta posible de influencia que conectara el marco corporal sólido inicial del progenitor con el de su cría, y que cada uno de los casos de variación y parecido puede ser "explicado" usando factores externos, las atribuciones hereditarias se convierten simplemente en una façon de parler.

Lo que quiero discutir, entonces, es la cuestión de la permeabilidad de las rutas causales hereditarias (posibles) a los factores externos durante el siglo XVIII. La tarea debería consistir en mostrar cómo autores diferentes con diferentes puntos de vista podían coordinar (y lo hicieron) los dos niveles de análisis: la influencia de los factores externos en la constitución corporal, y la influencia hereditaria de la constitución corporal de los padres en la constitución corporal del hijo.

La discusión específica en torno a la transmisión hereditaria de las enfermedades en el marco de las posturas dieciochescas sobre la fisiología y la generación ofrece un acceso privilegiado a las resbaladizas conceptualizaciones de las posibles rutas mediante las cuales el ambiente podría afectar, de una forma drástica y más o menos permanente, la constitución de los individuos y los linajes.

\section{III}

Parece útil abordar la discusión de la herencia en el siglo XVIII siguiendo la sugerencia de Peter McLaughlin de que es necesario hacer "la distinción entre los dos tipos de herencia: la transmisión legaliforme de las formas que definen las especies, y la alteración o suplementación contingentes de esta transmisión por los rasgos de individuales". ${ }^{37}$ Me parece, sin embargo, que hay que hacer la distinción de otro modo y tener más cuidado con el

${ }^{36}$ Véanse Coleman 1984 y Williams 1994.

${ }^{37}$ En su "Preliminary Notes on Biological Notions of Heredity in the Enlightenment", 2000. 
empleo del vocabulario, porque, durante el siglo XVIII, lo que McLaughlin refiere como el primer tipo de herencia era considerado fuera del dominio de lo hereditario. En general, ninguna postura respecto a la generación hablaba de herencia para referirse a la transmisión "legaliforme" de las formas; ése es un uso adoptado hasta bien entrado el siglo XIX. Todos durante el siglo XVIII (tanto del bando preformacionista como del sucesionista) ${ }^{38}$ pensaban que la transmisión de la forma de una generación a otra se debía a una causa (o hecho) constante, invariable, que daba a las especies su fijeza y estabilidad, y no estaba relacionado con las contingencias de la genealogía. La idea de la preexistencia del germen, así como la de una producción controlada por leyes (sucesiva) del nuevo ser, fuese configurada por un molde, o conducida por una fuerza generativa, o por algún otro principio epigenético, compartían la idea de una estructura básica común para cada especie, sobre la cual los caracteres singulares, accidentales de los ancestros no tenían influencia permanente. Por consiguiente, una actitud compartida hacia las características hereditarias (las peculiaridades del individuo, de la familia o de los principales linajes) era confinarlas al dominio de lo accidental. Si bien se aceptaban y discutían tanto en los tratados hipocráticos como en las obras de Aristóteles, los hechos de la transmisión hereditaria del parecido físico y moral, la deformación y la enfermedad fueron vistas como datos fácticos innegables (aunque fastidiosos) que tenían que ser explicados de alguna manera. Tal vez sólo en la tradición médica, con su preocupación por la singularidad de la enfermedad y los pacientes, se abrió más espacio a la reflexión acerca de las peculiaridades de los temperamentos individuales y su transmisión a través de la línea familiar. La distinción a la que McLaughlin apunta debe referirse entonces, para el periodo, como la de "tipo-accidente" y limitar sólo a lo segundo el ámbito de lo hereditario.

La distinción "tipo-accidente" permite un seguimiento cuidadoso del lugar que ocupó lo hereditario en distintos marcos teóricos. Por ejemplo, los médicos hipocrático-galénicos se contentaban con el hecho de que el modelo pangenético, de doble simiente, de solidificación de fluidos, podía, entre otras virtudes explicativas, dar cuenta de los datos de las recurrencias hereditarias. Al mismo tiempo, se consideró que el modelo de la generación más sofisticado teóricamente que concibió Aristóteles daba pie a algunos enigmas difíciles de resolver, en relación con esta clase de hechos. ${ }^{39}$ Hay de hecho una discusión actual entre los especialistas en Aristóteles acerca

\footnotetext{
${ }^{38}$ Sucesionista, como dije, es una etiqueta que incluye tanto a epigenetistas como a los partidarios de la formación rápida de doble simiente del germen, o primer rudimento.

${ }^{39} \mathrm{Al}$ menos desde la época de Empédocles, a cualquiera que le interesara dar una explicación de la generación humana (y animal), las paradojas de lo hereditario fueron un serio escollo: la postura de Aristóteles de la semilla masculina como único contribuyente causal a la forma del cuerpo de la descendencia tenía que esquivar la evidencia empírica de las características (similitudes, moldes) transmitidas por la hembra. La versión más convincente
} 
de cómo entender su propósito de explicar en su esquema (dar cuenta de él de algún modo) el hecho hereditario del parecido con ambos padres, y a veces con algunos ancestros.

Como es bien sabido, en el esquema aristotélico de la generación, la semilla masculina era la responsable de la forma y la femenina intervenía en las particularidades del individuo. ${ }^{40}$ En un reciente y esclarecedor texto, Andrew Coles ofrece un análisis fisiológico complejo del origen y la función de la semilla masculina (semen) en Aristóteles, de modo que quedan superadas las principales dificultades que surgen con los hechos hereditarios. Contra lo que se suele creer, según Coles, nuestro naturalista lo logró rescatando la noción cnidiana (hipocrática) del origen pangenético del semen: "Es en la concepción aristotélica de los orígenes fisiológicos del semen, y más en particular de sus propiedades hereditarias, donde los vínculos entre su biología y la de los cnidianos se acercan más." ${ }^{41}$ Aparentemente, esta postura consiste en que el semen (simiente masculina) es producto de un proceso especial de separación de la sangre, y que en su paso por todas las distintas partes del cuerpo del padre adquiere tipos particulares de capacidades (dunamis) secundarias que pueden ser los causantes de que continúen las similitudes hereditarias de la descendencia. El resultado de la lucha (parte por parte) de estas dunamis paternales con capacidades similares que se oponen a ellas, y que llegan en la materia generativa de la madre, define a qué lado saldrán las distintas partes del hijo. ${ }^{42}$

La aguda percepción aristotélica de los espinosos problemas causales que planteaban las similitudes hereditarias al parecer fue diluida progresivamente por sus intérpretes, de modo que los aspectos de su sistema específicamente diseñados para lidiar con ellos parecen haberse perdido. Galeno, por ejemplo, estaba convencido de que no había manera de que Aristóteles pudiese explicar las similitudes transmitidas por la madre, y por esa razón planteó un argumento contundente en favor de la existencia de una simiente femenina, con facultades fisiológicas equivalentes para transmitir peculiaridades hereditarias. ${ }^{43}$

Harvey creía ser aristotélico cuando restringía la influencia material de la fisiología a la acción de los espíritus masculinos en la producción (concepción) de la forma en el nuevo ser, y orilló la influencia (similitudes,

de las mezclas irregulares del parecido con ambos padres provino de las teorías de doble simiente.

${ }^{40}$ La cuestión, entonces, como la plantea Sharples 1985, es que si se supone que el padre imparte la forma y nada más, ¿̇por qué los padres de nariz respingada tienden a tener hijos de nariz respingada? Véase Sharples 1985.

${ }^{41}$ Véase Coles 1995, p. 50.

42 Véase ibid., pp. 70-76.

${ }^{43}$ Véanse Coles 1995, p. 76, y Boylan 1984. 
etc.) hereditaria al dominio paracelsiano de la acción de la imaginación de la madre. ${ }^{44}$

Como señala McLaughlin, el conflicto entre modelos pangenéticos (de doble simiente) de la generación (con su apoyo en lo hereditario) y las exigencias epistemológicas (y teológicas) que promovían las posturas preformacionistas produjo, en el siglo XVII, diferentes intentos por combinar las virtudes de ambas explicaciones, como aparentemente lo había hecho Aristóteles.

A principios del siglo XVIII, Bourguet propuso un modelo sintético de ese tipo: un germen preformado afectado después de la fecundación por una influencia pangenética, de doble simiente, causante de todos los rasgos hereditarios.

Como se ha dicho, Haller usó primero lo hereditario como un arma para la epigénesis sucesionista, y más adelante cambió de lado y negó enfáticamente su realidad cuando criticó a Buffon.

Bonnet, a su vez, adoptó la estrategia de Bourguet al separar claramente el origen de la forma (en el germen) y los orígenes externos de las similitudes, ${ }^{45}$ que obedecían a la incorporación (intususcepción) de los accidentes en el proceso de crecimiento-desarrollo nutricional, en el cual podían intervenir partículas (pangenéticamente reunidas) de ambos orígenes. Aunque autores sucesionistas como Maupertuis y Buffon insistieron en que es importante la manera (nueva) en que se produce el germen en cada fecundación, varios autores ${ }^{46}$ han sostenido que hay una estructura común entre su hipótesis y un preformacionismo complicado como el que propone Bonnet. Hace más de cien años, en un ensayo histórico perspicaz llamado "Evolution in Biology" (1878), T.H. Huxley llegó a la conclusión de que si hacemos a un lado el tiempo y la manera en que se produce el germen (el rudimento de Harvey), la mayoría de los teóricos dieciochescos de la generación, preformacionistas o sucesionistas, apoyaba alguna forma de la doctrina de la evolución o el desarrollo, que considera una fase doble en la producción del cuerpo del nuevo ser; en primer lugar, la creación o reproducción de la estructura básica en el germen, y en segundo el crecimiento y el desarrollo de este rudimento. ${ }^{47}$ Huxley ve en la descripción de Bonnet de tal proceso el "ejemplar" común de la época. Para el caso del huevo de la gallina, Bonnet en sus Considérations... afirma lo siguiente:

\footnotetext{
44 Véase Harvey 1651.

45 Aunque, en las últimas versiones de su teoría de la generación, Bonnet se acercó cada vez más a un esquema protoepigenético, en el cual la estructura organizada no está realmente presente en el germen preformado, sino de algún modo "preprogramada". Véanse Huxley 1878, y Bonnet 1779 .

${ }^{46}$ Incluido en McLaughlin 2000.

${ }^{47}$ Incluso Cuvier en el siguiente siglo [XIX] adoptó un esquema similar, añade T.H. Huxley (1878, p. 190).
} 
la fecundación y la incubación simplemente causan que el germen absorba las materias nutritivas, que se depositan en los intersticios de las estructuras elementales de las cuales se forma el polluelo miniatura, o germen. La consecuencia de este crecimiento intususceptivo es el "desarrollo" o "evolución" del germen para convertirse en el ave visible. Así, un individuo organizado es un cuerpo compuesto que consiste en las partes originales, o elementales, y en las materias que se han asociado a ellas con ayuda de la nutrición, de modo que si estas materias pudieran ser extraídas del individuo, por así decirlo, éste terminaría concentrándose en un punto, y se restauraría de este modo su condición primitiva de germen. ${ }^{48}$

Modificaciones posteriores a esta noción de germen hicieron que la posición de Bonnet fuera todavía más general e inclusiva: ${ }^{49}$ "Esta palabra (germen) no sólo designará un cuerpo organizado reducido en pequeño; designará incluso toda especie de preformación original de la que puede resultar un todo orgánico (un individuo), así como su principio inmediato." 50 La conclusión de Huxley es elocuente: "Pero así definido, el germen no es ni más ni menos que la 'particula genitalis' de Aristóteles, o el 'primodium vegetale' u 'ovum' de Harvey; y la 'evolución' de tal germen no se podría distinguir de la 'epigénesis'."

Así, aun algo tan obtuso como el "molde interior" de Buffon podía verse, desde esa perspectiva, como equivalente al "germen" generalizado de Bonnet. Pese a importantes sutilezas que se dejaron de lado cuando Huxley integró grosso modo estos conceptos, sin duda él está señalando algo importante. La mayoría de los teóricos del siglo XviII compartían la idea de que hay un hiato conceptual profundo entre la explicación de la organización (similitudes taxonómicas) y la de peculiaridades individuales accidentales (variaciones, similitudes).

Para nuestros fines, la similitud que ve Huxley entre los modelos de la generación del tipo Bonnet-Haller y los del tipo Buffon-Maupertuis gira en torno al hecho de que ambos suministran un germen que sufre un proceso de crecimiento y transformación bajo la influencia de un medio fluido que ofrece los elementos que terminan siendo incorporados. Este medio explica la influencia hereditaria. El origen, las cualidades y la manera de la acción se convierten en tema de las consideraciones hereditarias. Los rasgos permanentes, esenciales, tipológicos de la organización se identifican con el marco sólido; mientras que los rasgos accidentales, efímeros, entran en

${ }^{48}$ Huxley 1878, p. 191.

${ }^{49}$ Huxley dice: "Bonnet [...], en sus escritos posteriores, por fin [. . .] admite que el germen no tiene por qué ser la miniatura real del organismo, que tal vez sea meramente una 'preformación original' capaz de producir a aquél”, en 1878, p. 193, donde cita a Bonnet 1779, parte X, cap. II.

50 Bonnet 1779, parte X, cap. ii, citado por Huxley 1878, p. 193.

${ }^{51}$ Huxley 1878, p. 193. 
juego mediante las influencias humorales (de los fluidos). La dialéctica de la interacción sólido-humoral tiene un papel decisivo en la separación entre la estabilidad estructural y las desviaciones individuales. La organización sólida (dada, por ejemplo, por el germen o conducida por una fuerza solidificante) recibe influencias constantes y materia del ambiente fluido; éstas alteran y modelan el marco corporal.

La agregación o intususcepción de partículas de diferentes orígenes (paternos, maternos, externos) son procesos que a la ruta hereditaria le son indiferentes. Tanto una explicación sucesionista como una preformacionista de la generación pueden igualmente explicar (o desembarazarse de la necesidad de explicar) la transmisión hereditaria mediante la incorporación de elementos durante el crecimiento o el desarrollo.

Hay una diferencia importante que se debe tener presente acerca de las consecuencias de aceptar la explicación preformacionista y las de una explicación sucesionista del origen del germen (o "primera formación"). Aunque en ambos casos se pueden explicar algunos hechos hereditarios mediante los suplementos externos ${ }^{52}$ a la primera formación durante la "evolución", o crecimiento, la preservación de una separación nítida entre el origen (causal) de la forma y el origen (causal) de las similitudes o degeneraciones se vuelve más problemático para el sucesionista. En un modelo del tipo Maupertuis-Buffon, por ejemplo, algunas de las variaciones hereditarias importantes más drásticas (degeneraciones) podían ser incorporadas, hasta cierto punto, en la secuencia genealógica esencial; la polidactilia, u otras degeneraciones, puede ser transmitida o "copiada" mediante el proceso de la generación ${ }^{53}$ causante de la primera formación, de manera similar a como ocurre con las características más básicas de la especie. De hecho, para algunos defensores de la preformación, como Haller, esta vaguedad acerca de los límites de lo individual (similitudes) y lo formal (tipos) se convirtió en una de las principales razones para oponerse a los esquemas sucesionistas. Al mismo tiempo, el hecho de que la preformación no explicara (por sí sola) la persistencia en las líneas genealógicas de los rasgos accidentales hizo que el recurso subsecuente a una influencia pangenética suplementaria (de doble simiente) resultara metodológicamente sospechoso. ${ }^{54}$ De nuevo, la permeabilidad o impermeabilidad de la forma específica a influencias accidentales externas es una de las cuestiones que están en juego en estas discusiones.

${ }^{52}$ De doble simiente, más sangre materna, más otras fuentes de nutrimento.

${ }^{53}$ V.gr., mediante el molde interior modificado, o la memoria material de Maupertuis. En los escritos de Buffon parece haber evidencia en favor de una posibilidad de modificación del molde interior, así como en favor de su inalterabilidad. Véase Aréchiga 1996.

${ }^{54}$ En su obra de 1878, Huxley concluye que sólo cuando C.F. Wolff observó cuidadosamente el desarrollo del polluelo terminó el impasse especulativo, y la embriología pudo tomar una ruta progresiva. 
Aunque hay que recordar que los hechos hereditarios podían tener, todavía durante el siglo XVIII, explicaciones no fisiológicas (v.gr., la constancia o repetición de algunas influencias climáticas externas, o apelando a la acción de la imaginación u otras intervenciones de la "mente sobre la materia"), la búsqueda de una fuente fisiológica estable y regular se fue viendo cada vez más como la única estrategia explicativa sensata. Para una estrategia de este tipo, había una pregunta importante que giraba alrededor del origen, el tipo y las cualidades de las partículas materiales que fueron incorporadas (mediante la generación, la nutrición, el desarrollo y el crecimiento) en las diferentes partes del cuerpo. La noción de una frontera ontológica estricta entre partículas orgánicas e inorgánicas, como propuso, por ejemplo, Buffon, ofreció otra frontera que había que tener en cuenta. $\mathrm{El}$ acceso de las influencias externas a los rasgos corporales distintivos de cada individuo podía claramente ser limitado por tales consideraciones. Las climáticas, las nutricionales y otras fuentes de variación corporal (capturadas elocuentemente en la etiqueta de las cosas no naturales) pueden tener muy diferente capacidad para alterar la constitución conforme a la continuidad o discontinuidad postulada entre constituyentes corporales y materia externa (aire, agua, lugares...). En mi opinión, el marco médico de influencias naturales y no naturales, y de sólidas frente a humorales, era el principal recurso que se tenía para lidiar con estas cuestiones; sin duda estaba en la raíz de las especulaciones de Buffon concernientes a la influencia del clima y la alimentación en la producción de degeneraciones, que comienzan como variaciones individuales y se generalizan progresivamente en un linaje, ya que se transmiten hereditariamente ("tal como las enfermedades se transmiten del padre o la madre al hijo"). ${ }^{55}$

Otro problema que no se suele formular claramente es la "persistencia" (que las hace más o menos permanentes o efímeras) de las peculiaridades incorporadas por las rutas ambientales y nutricionales, en el marco de las sucesiones genealógicas. Esta cuestión se puede volver crucial en una explicación sucesionista si hay una dilución de la diferencia entre organización individual y específica. ${ }^{56} \mathrm{El}$ problema se les presentó a Maupertuis y a Buffon, y también a Blumenbach. Los tres postulaban una transformación semipermanente del tipo debido a la conservación de variaciones accidentales en el linaje. ${ }^{57}$ Es probablemente en las extensas discusiones de Buffon sobre la noción de degeneración donde las complejidades de este

\footnotetext{
${ }^{55}$ Véase Buffon 1749. Véase también Aréchiga 1996, p. 74.

${ }^{56} \mathrm{El}$ proceso de usar la constitución corporal o el temperamento completo de uno de los progenitores como un patrón o molde original para la producción del nuevo ser (en el momento de su primera formación) ha inducido incluso a que se hable paradójicamente de la conservación de un tipo individual (!). Véanse Duchesneau 1982, p. 539, y López-Beltrán 1992.

57 John Hunter llegó a una postura similar, con la influencia de Blumenbach. Véase LópezBeltrán 1992.
} 
tema comenzaron a ser resueltas. La creencia en una correlación estricta y generalizada entre clima y temperamento corporal en grupos humanos fue duramente cuestionada en el curso del siglo XVIII. La tenacidad $y$ la debilidad (i.e. diferencias en "persistencia") de los rasgos raciales accidentales tuvieron tanto evidencias como testimonios en su favor. ${ }^{58} \mathrm{El}$ problema de establecer cómo y cuándo la influencia externa en las características físicas se "arraigaba" 59 en un linaje adquirió importancia progresiva después de la obra de Buffon. Este autor francés siempre sostuvo que existía un límite para la cantidad y el tipo de variación aceptada por el molde interior. ${ }^{60}$

Kant, por su parte, creyó en la debilidad de las adquisiciones accidentales:

Gradualmente, por lo menos, la constitución del suelo (humedad o sequía), y de la alimentación también, induce una diferencia hereditaria o variedad entre animales del mismo ganado y la misma raza, especialmente en talla, proporción de las extremidades, y también en el temperamento; que más adelante se hibridiza cuando se mezcla con otro tipo; pero sobre otro suelo y en presencia de otro tipo de alimento (aun sin alteración del clima) desaparece en unas cuantas generaciones. ${ }^{61}$

Blumenbach, a su vez, vaciló ante la evidencia. Después de haber descartado también la postura de que lo que Buffon llamaba degeneraciones se podía convertir en una parte hereditaria estable de la constitución de un animal (o de una persona), llegó a aceptar lo que denominó "peculiaridades hereditarias de los animales ocasionadas por temperamentos enfermos":

A primera vista parecería que una disposición hereditaria a la enfermedad pertenece más bien a la patología que a la historia natural de los animales. Pero cuando se examina el asunto con mayor detenimiento, queda claro que hay más de una forma en la que tiene algo que ver con aquellas causas de degeneración que nos ocupan. ${ }^{62}$

${ }^{58}$ Escribe Blumenbach: "tal es la diferencia de sus efectos [...]; [algunos] se conservan perfectos por un tipo de constancia tenaz durante largas series de generaciones, o, por alguna facultad de cambio, se retiran de nuevo en un lapso breve". (Blumenbach 1865) Véanse Roger 1989, Aréchiga 1996 y Glacken 1967.

${ }^{59}$ Su metáfora de la profundidad, del arraigo, tomada, en mi opinión, de especulaciones iatroquímicas de la semilla o la causa material de la enfermedad, se invocó con frecuencia en este contexto.

${ }^{60}$ Blumenbach mismo titubeó ante la evidencia. Compárense Blumenbach 1775 y 1795. Véase también López-Beltrán 1992.

${ }^{61}$ Kant 1775, en Chukwudi 1997.

62 Blumenbach 1865, específicamente "On the Natural Varieties of Mankind”, 3a. ed., 1895, p. 202. 
Blumenbach escribe posteriormente que cuando alguno de éstos (enfermedades o trastornos de constitución...) se propaga por causas hereditarias durante una larga secuencia de generaciones, termina fundiéndose sensiblemente en un tipo de segunda naturaleza, y en algunas especies de animales da pie a variedades peculiares y constantes. ${ }^{63}$

IV

La analogía que Blumenbach estableció entre enfermedad hereditaria y variación hereditaria, y la forma en que borra la distinción son, en mi opinión, reveladoras, en cuanto a que dentro de la tradición médica existía un marco que permitía abordar los problemas del vínculo entre el cuerpo (temperamento, constitución) y el ambiente. En éste se podían contemplar conjuntos de factores causales complejos, y mutuamente dependientes, actuando sobre el mismo efecto (el cuerpo), de tal forma que el resultado final no pudiese ser atribuido por completo a una u otra influencia particular. Las nociones de crasis (mezcla), fluidez, individualidad, permitían que la imaginación concibiera un resultado dado como determinado y causado, y también como un producto complejo de un conjunto variable e inanalizable. Por otro lado, la distinción entre cosas naturales (marco corporal, temperamento) y cosas no naturales (que afectan y cambian a aquéllas) permitía una separación de espacios causales que es, empero, muy diferente de la separación moderna naturaleza-crianza a la que nos hemos habituado. Por ejemplo, el hecho de que pasiones, sueños y otros elementos psicológicos fueran situados en el mismo nivel que el aire, la comida o el agua, revela una concepción muy diferente de las fronteras y de las dependencias causales que están implicadas. Los organismos (los cuerpos), más que estar, como los concebimos hoy, en una secuencia dialéctica de expresión (frente a un medio) y transmisión a la siguiente generación del material hereditario, eran concebidos inmersos en su entorno, abiertos a él e íntimamente dependientes de él. La compleja malla de influencias que afectaban a cada organismo particular era el tema y la preocupación de la tradición médica, y la herencia física y moral que pasaba de progenitores a vástagos a través de la reproducción constituía sólo una porción pequeña de ésta.

Las cosas naturales (humores, elementos, temperamento) pueden equipararse sin distorsión con los constituyentes del cuerpo de los que es responsable la generación. Es decir, el germen, o el conjunto preordenado de elementos que se unen para dar cuerpo al nuevo individuo organizado, es el efecto de las cosas naturales. Las cosas no naturales (aire, alimentos, sueños, pasiones, etc.) forman el conjunto de influencias "externas" que de

${ }^{63}$ Ibid., p. 259. 
algún modo entran en contacto con el cuerpo, o que lo afectan determinantemente a medida que crece, vive y decae. Un análisis somero puede describir estos dos conjuntos de causas como desconectadas o independientes. Es significativo, por ejemplo, el hecho de que fueran abordados en dos tratados hipocráticos diferentes. ${ }^{64}$ Pero, por supuesto, el vínculo entre ellos es poderoso, y como Arnulfe D'Aumont insiste, cuando esta interacción (natural/no natural) se desbalancea aparece lo præter-natural (la enfermedad). ${ }^{65}$ Como vimos antes, en el argumento de Antoine Louis, estos seis no naturales pueden fácilmente tener pertinencia en la discusión concerniente a las causas externas de degeneración, y la "persistencia" que adquieren conforme a su origen y momento de influencia. ${ }^{66}$ Médicos de distintas orientaciones consideraban más o menos abierta la posibilidad de que, a través de la generación, las influencias externas se volviesen más o menos permanentes dentro de una línea genealógica.

Un acceso privilegiado a cómo se abordaron estos asuntos, y a los detalles de la fisiología y la etiología, durante el siglo XVIII, lo tenemos cuando examinamos las discusiones del periodo en torno a las enfermedades hereditarias. ${ }^{67}$ Con base en ellas podemos aclararnos las distintas consecuencias para la fenomenología de lo hereditario que los médicos veían cuando aceptaban o rechazaban la apertura (permeabilidad) de la primera formación ante causas accidentales externas. Distintas fronteras podían establecerse dependiendo de las diferentes posturas fisiológicas. Hay para ello que recuperar la pregunta de si acaso los rasgos corporales hereditarios accidentales son inducidos por los seis no naturales, y añadirle la de si estas transformaciones son de un orden tal que el linaje familiar se vea afectado de manera permanente. En los siguientes párrafos intentaré resumir brevemente varias posiciones que se pueden encontrar entre los médicos durante la segunda mitad del siglo XVIII.

Una posición solidista estricta puede conducir de inmediato a un punto de vista antihereditario; hemos visto eso con Louis: ${ }^{68}$ la imposibilidad de la incorporación (en el nivel de profundidad requerido) de algo externo o

64 “Airs, Waters, Places” y “The Nature of Man”, en Hipócrates 1923.

65 D'Aumont 1765.

${ }^{66}$ La división que describimos entre humoralistas y solidistas cobra relevancia. Desde un punto de vista humoralista, el equilibrio entre humores es crucial, y hay un flujo continuo de materiales, mezclas, dentro y fuera del cuerpo, transportados por el aire, los líquidos y los alimentos. Las partes sólidas del cuerpo están siempre cambiando de acuerdo con estas interacciones. Desde un punto de vista solidista, la raíz de la enfermedad está en una lesión o malformación en el nivel de los órganos o partes sólidas. Son los sólidos y sus propiedades los que dominan o controlan los humores.

${ }^{67} \mathrm{He}$ hecho un estudio minucioso de los debates en torno a este tema, ocurridos en Francia entre 1745 y 1810, en López-Beltrán 1997.

${ }^{68}$ El propio Louis sitúa la confianza de su argumento antihereditario en la vieja obra de Luis Mercado, donde aparentemente también se niega toda influencia de sólido a sólido. Véase Louis 1749. 
accidental en el marco corporal (i.e., el germen original). éste es el principal argumento de Louis. Si las enfermedades tienen una raíz solidista, cualquier lesión tendría que ser local, aislada, y sus efectos terminarían con la muerte del lesionado. En contraste, una postura humoralista incorpora lo hereditario a una coreografía de influencias internas y externas; en ellas no hay una separación nítida entre humores externos e internos. La influencia hereditaria no tiene un estatuto (ontológico) especial; es más bien una consecuencia (un "efecto secundario") del flujo de generaciones sucesivas que adquieren y alcanzan a veces a transmitir a la descendencia (mediante la generación) peculiaridades físicas (y morales). A lo más, el adjetivo "hereditario" hace referencia a una posible ruta de transmisión de influencias que también actúan por otras vías.

Un desarrollo teórico importante ocurre entre los médicos cuando solidistas comprometidos, no muy satisfechos con las explicaciones humorales proteicas de las enfermedades de origen hereditario, aceptan, sin embargo, la realidad del hecho de la transmisión hereditaria, basándose en el peso de la evidencia que aportan los casos acumulados de rasgos y enfermedades que recorren linajes. Se reconoce así un nuevo tipo de especulación acerca de la posibilidad de influencia hereditaria de sólido a sólido, y como consecuencia se propone una distinción entre la transmisión propiamente hereditaria y las influencias congénitas paralelas. ${ }^{69}$

También podríamos resumir los diferentes "modelos" de la transmisión de enfermedades hereditarias atendiendo a la noción de la generación que presuponen los médicos. Según la preformación: el germen es invadido por la "semilla" de la enfermedad, ${ }^{70}$ y su equilibrio humoral se ve alterado; o bien, es dañado por una influencia externa ( $v . g r$., un fluido) durante su desarrollo y la alteración puede entonces transmitirse de algún modo a la siguiente generación mediante la simiente parental (pangenéticamente). De modo que la transmisión no es inevitable. En una explicación sucesionista puede suceder algo análogo. Después de la "primera formación", se pueden sufrir alteraciones heredables; los humores son la causa de las idiosincrasias. No hay una distinción etiológica importante entre recibir la mala acción por primera vez en el linaje (por una causa ambiental) o recibirlo a través de los líquidos de los padres durante el crecimiento y el desarrollo, o incluso durante la crianza.

En la tradición solidista, hacia fines del siglo XVIII, se comienza a bosquejar una idea muy diferente de transmisión hereditaria que sólo es posible en un esquema sucesionista. Se propone alguna forma de mecanismo copiador como responsable de producir, en cada generación, las partes sóli-

\footnotetext{
69 Para un análisis detallado de esta innovación conceptual, y sus consecuencias tanto en las discusiones francesas como en las británicas de lo hereditario, véase López-Beltrán 1992, 1997.

${ }^{70}$ De una forma iatroquímica.
} 
das del nuevo ser. ${ }^{71}$ Esto último podría enmarcarse (como hicieron Buffon y Maupertuis) bajo la analogía de la cristalización. Se considera que los cuerpos (sólidos) de los progenitores son la fuente (o el molde) que se usa como base para producir la nueva organización en el hijo. Tanto los rasgos esenciales como los no esenciales pueden entonces ser candidatos a ser reproducidos por los mecanismos copiadores. Bajo esta óptica, el suceso hereditario (la transmisión de peculiaridades) ocurre siempre en el momento de la "primera formación" de las partes sólidas (la producción del germen). Las variaciones corporales atribuibles a la influencia externa se pueden convertir en hereditarias sólo si se originan en el momento de la "primera formación". Además, no todo rasgo se transmite exactamente de la misma manera. Hay más bien una tendencia diferente entre ellos a ser transmitidos según ciertas propiedades. Los rasgos esenciales se transmiten con más constancia, y los rasgos accidentales tienen menos oportunidad de ser copiados. Las similitudes tienen más abierto el camino que las degeneraciones. Mientras más antiguo es un rasgo en un linaje, más fuerte será su tendencia a transmitirse debido a cierto arraigo que habrá generado ya. Lo que hemos estado llamando la "persistencia" de una variación se vincula, por tanto, a su propensión a ser arrastrada a generaciones posteriores mediante el mecanismo "copiador". Así se explica la variación en la descendencia. La organización corporal del nuevo ser es una versión de la organización de los progenitores, de donde se copian tanto los rasgos esenciales como los accidentales. Aun las deformidades se pueden transmitir si su origen es un accidente ocurrido en el momento de la primera formación; esto es lo que se puede denominar una explicación de la transmisión hereditaria de la variación accidental debida a causas externas por un "accidente incorporado". Esta forma de pensar se puede encontrar esbozada en el modelo de la generación de Maupertuis, y fue usada después por John Hunter en Inglaterra. La distinción nítida que pretende establecer entre la transmisión hereditaria y la no hereditaria dentro de los linajes fue utilizada por los médicos franceses, y también por Hunter y sus seguidores, para marcar una diferencia entre transmisión de enfermedades congénita e innata (connate).$^{72}$ Lo que a menudo se discute -insistoes la profundidad de la incorporación de las variaciones hereditarias en el flujo normal conducido por el mecanismo de reproducción. Normalmente, entre los médicos, la pregunta que se aborda es cómo se puede eliminar la enfermedad hereditaria, si acaso hay manera de hacerlo. La respuesta a dicha pregunta refleja la postura que sostiene el médico. Los humoralistas son menos fatalistas al respecto, pues en su visión la transmisión del mal hereditario es evitable limpiando de algún modo la simiente. ${ }^{73}$

\footnotetext{
${ }^{71}$ Véase Pujol 1802; también Prichard 1813, 1826.

72 Véanse Pagès 1798; Pujol 1802, y Adams 1814.

${ }^{73}$ Véase López-Beltrán 1997.
} 


\section{CONCLUSiOnes}

Con base en lo dicho hasta aquí, podemos hablar de que durante el siglo XVIII existen dos tipos de obstáculos o fronteras para la noción de transmisión hereditaria. Se puede considerar que la "canalización" de las influencias hereditarias por la "línea de producción" fisiológica de los nuevos seres durante el siglo XVIII estuvo delimitada por una frontera interna y otra externa. La frontera interna se define por la separación entre la reproducción (generación tras generación) de la forma específica, y la adquisición y la transmisión de accidentes peculiares de constitución por parte de individuos y linajes. Tanto el punto de vista preformacionista como el epigenetista de la generación aceptaron el reto de explicar los hechos (o de dar cuenta de ellos de algún modo) acerca de los vínculos hereditarios entre padres e hijos. En ambas posiciones se colocó una frontera estricta a fin de preservar la integridad y la estabilidad de la forma. Los accidentes no se veían como incorporables definitivamente a los rasgos organizativos esenciales, es decir, a la forma. Todo nuevo ser, al integrarse como un germen, estaba libre de los accidentes debido a lo exterior, incluido lo hereditario.

La frontera externa se define por los hechos fisiológicos del crecimiento, el desarrollo y la nutrición. De la cantidad de aislamiento que se consideraba que mantenían estos procesos con respecto al entorno físico dependía la cantidad de variación regular aceptada para el crecimiento y el desarrollo (i.e. para el temperamento del individuo maduro). Está claro, además, que las nociones sobre la profundidad de los cambios también podían variar. Muchos compartían la creencia de que sólo las modificaciones en el temperamento causadas por las cosas no naturales lograban abrirse paso hacia el flujo de la cadena pangenética de la transmisión. El misterio, por supuesto, era definir cómo podía ocurrir esto realmente. ¿Qué es exactamente lo que tenían que modificar las influencias externas para hacer permanentes sus efectos? ¿El molde o las partículas? Buffon, Blumenbach y otros pensadores del siglo XVIII concibieron los mecanismos mediante los cuales las modificaciones físicas inducidas por el ambiente podían preservarse hereditariamente y dar lugar a variedades dentro de las especies. La reversibilidad debido a influencias externas fue siempre una opción que considerar, como lo fue la idea del mejoramiento físico de las especies, sobre todo de los humanos, por medio de las medidas higienistas. ${ }^{74}$ En Francia, el programa vitalista mantuvo esta actitud a lo largo del siglo XIX, lo que permitió que la idea de determinación hereditaria de los caracteres físicos y morales se viera equilibrada por una contrapartida higienista.

Con todo, la idea de transmisión hereditaria fue restringida y tuvo una importancia menor en el siglo XVIII. Al rompimiento de lo que acabo de llamar la frontera interna se puede atribuir el endurecimiento de la he-

\footnotetext{
${ }^{74}$ Trasladarse a otros climas, cambiar la dieta o la forma de vida.
} 
rencia y su transformación progresiva, durante el siglo XIX, en una causa central del pensamiento fisiológico. La permanencia y la trascendencia de las variaciones "accidentales" necesitaban una nueva conceptualización de lo hereditario. A finales del siglo XVIII y principios del XIX, las estrechas fronteras entre las cuales era concebible que ocurriera la transmisión hereditaria se fueron rompiendo y se borraron progresivamente, como se puede observar en las cambiantes posturas de Blumenbach, y con más prominencia en el uso lamarckiano de las modificaciones hereditarias (y en un sentido "accidentales") como la fuente de la transformación de las especies. El resultado de esta apertura fue que entonces se pudo considerar que las causas externas climáticas y psicológicas afectaban y modificaban a largo plazo la forma esencial de los organismos y de sus descendientes. Se podía pensar que algunas degeneraciones - que tocaban profundamente la constitución del organismo- poseían una considerable persistencia y eran así testimonio del poder, tanto del ambiente como de la herencia, para dar forma a los cuerpos (y a las mentes). Entonces fue posible ver que las similitudes, las degeneraciones y la transmisión de la forma a través de la generación tenían dependencias causales estrechamente vinculadas.

\section{BIBLIOGRAFÍA}

Adams, Joseph, 1814, A Treatise on the Hereditary Properties of Diseases, J. Callow, Londres (edición facsimilar en Charles Rosenberg's series, History of Hereditarian Thought, Garland Publishing, 1984); 2a. ed. ampliada con apéndices: A Philosophical Dissertation on the Hereditary Peculiarities of the Human Constitution, 1815; trad. al alemán en Neu Sammlung auserlesener Abhandlungen, tomo II, p. 503.

Amoreux Pierre-Joseph, c. 1790, "Des Maladies Héréditaires", manuscrito en archivos de la Real Sociedad de Medicina de París (10; 120-3-1).

Anderson, James, 1799, "An Inquiry into the Nature of that Department of Natural History which Is Called varieties", en Recreations in Agriculture, Natural-History, Arts, and Miscellaneous Literature, T. Bensley, Londres (6 vols., 17991806), vol. 1, pp. 49-100.

Arbuthnot, J., 1733, Essay Concerning the Effect of Air on Human Bodies, Londres.

Aréchiga, Violeta, 1996, El concepto de 'degeneración' en Buffon, tesis de maestría, Universidad Autónoma Metropolitana-Iztapalapa.

Bénichou, Claude (ed.), 1989, L 'Ordre des caractères. Aspects de l'hérédité dans l'histoire des sciences de l'homme, Vrin, París.

Bernardi, Walter, 1986, Le Metafisiche dell'Embrione; Scienze della vita e filosofia da Malpighi a Spallanzani (1672-1793), Leo S. Olschki, Florencia.

Bichat, M.F.X, 1800 (an VIII), Recherches physiologiques sur la vie et la mort, Brosson \& Gabon, París.

Blumenbach, J.F., 1865, The Anthropological Treatises (Translations by T. Bendysche of his Works On the Natural Variety of Mankind of 1775 and 1795), Anthropological Society, Londres. 
Böhme, Gernot y Hartmut Böhme, 1998, Fuego, agua, tierra, aire. Una historia cultural de los elementos, trad. Pedro Madrigal, Herder, Madrid (original de 1996).

Bonnet, Charles, 1779, Considérations sur les corps organisés, vol. 3 de las OEuvres d'histoire naturelle et de philosophie, Neuchatel, Ginebra, 8 vols. Hay una reproducción (1985) de la edición de 1778 en la colección Corpus des OEuvres de Philosophie an Langue Francaise, de Fayard.

— 1769, La paligénésie philosophique, Ginebra.

Borie, Jean, 1981, Les Mythologies de l'Hérédité au XIX ${ }^{e}$ siècle, Galilée, París.

Bowler, P.J., 1989, The Mendelian Revolution, Athlone Press, Londres.

— 1973 , "Bonnet \& Buffon - Theories of Generation and the Problem of Species”, Journal of the History of Biology, vol. 6 (otoño), pp. 259-281.

- 1971, "Preformation and Pre-existence in the $17^{\text {th }}$ Century", Journal of the History of Biology, vol. 4, no. 2 (otoño), pp. 221-244.

Boylan, Michael, 1986, "Galen's Conception Theory", en Journal of the History of Biology, vol. 19 (primavera), pp. 47-77.

_ 1984, "The Galenic and Hippocratic Challenges to Aristotle's Conception Theory", en Journal of the History of Biology, vol. 17 (primavera), pp. 83-112.

Buffon, Georges Louis Leclerc Conde de, 1749, "Histoire Naturelle de l'Homme", en De l'Homme, 1971, París.

Burns, Chester R., 1976, "The Nonnaturals: A Paradox in the Western Concept of Health", The Journal of Medicine and Philosophy, vol. 1, no. 3, pp.202-211

Bynum, W.F., y Roy Porter, 1993, Companion Encyclopedia of the History of Medicine, Routledge, Londres.

Cabanis, P.J.G., 1802 (an X), Rapports du physique et du moral de l'homme, en OEuvres philosophiques de Cabanis, ed. Claude Lehec y Jean Cazeneuve, Presses Universitaires de France, París, 1956, 2 vols., vol. I, p. 126 [versión en inglés: On the Relations between the Physical and Moral Aspects of Men, Johns Hopkins University Press, 1981, 2 vols.].

Canguilhem, Georges, 1983, Études d'histoire et de philosophie des sciences, Vrin, París.

— - 1977, La Formation du concept de reflex aux XVII et XVIII siècles, Vrin, París.

Canguilhem, Georges, G. Lapassade, J.P. Piquemal y J. Ulmann, 1962, Du Développement a l'évolution au XIX ${ }^{e}$ siecle, Presses Universitaires de France, París (2a. ed.: 1985).

Chambers Dictionary - Cyclopedia or an Universal Dictionary of Arts \& Sciences, 2a. ed., ed. E. Chambers, Londres, 1738, 2 vols.

Chukwudi Eze, Emmanuel (comp.), 1997, Race and the Enlightenment: A Reader, Blackwell, Cambridge, Mass.

Churchill, Frederick, 1987, "From Heredity to Vererbung. The Transmission Problem 1850-1915”, Isis, vol. 78, pp. 337-364.

Coleman, William, 1984, "Inventig Demography, Montyon on Hygiene and the State", en E. Mendelsohn (comp.), Transformation and Tradition in the Sciences, Cambridge University Press, Cambridge.

— 1974 , "Health and Higiene in the Encyclopédie: A Medical Doctrine for the Bourgeosie", Journal of the History of Medicine, vol. 29, pp. 399-421.

— 1965, "Cell, Nucleus and Inheritance. A Historical Study", Proceedings of the American Philosophical Society, vol. 109, no. 3, junio, pp. 124-158. 
Coles, Andrew, 1995, "Biomedical Models of Reproduction in the Fifth Century B.C. and Aristotle's Generation of Animals" Phronesis, vol. XL, no. 1.

Corsi, Pietro, 1988, The Age of Lamarck. Evolutionary Theories in France 1790-1830, trad. J. Mandelbaum, University of California Press, Los Ángeles.

D’Aumont, Arnulfe, 1765, "Non-naturelles, choses", en D. Diderot y J. D'Alembert, Enciclopédie, vol. XI, pp. 217-224.

Diderot, D., 1964, Élemens de physiologie, ed. Jean Mayer, Marcel Didié, París (primera edición: 1875).

Diderot, Denis y Jean D'Alembert, 1750-1775, L'Encyclopédie, ou Dictionnaire des Sciences, Arts et Métiers.

Duchesneau, Francois, 1982, La Physiologie des Lumières; empirisme, modèles, théories, Martin Nijhoff, La Haye.

Fourke, Daniel C., 1989, "Mechanical and 'Organical' Models in Seventeenth-Century Explanations of Biological Reproduction", Science in Context, vol. 3, no. 2, pp. 365-381.

Fox, Christopher, Roy Porter y Robert Wokler (eds.), 1995, Inventing Human Science, Eighteenth-Century Domain, University of California Press, Los Ángeles.

Galton, Francis, 1889, Natural Inheritance, Macmillan, Londres.

—, 1872 , "On Blood-Relationship", Proceedings of the Royal Society (Londres), vol. 20, pp. 394-402.

— 1869, Hereditary Genius, Macmillan, Londres.

Gayon, Jean, 1998, Darwinism's Struggle for Survival: Heredity and the Hypothesis of Natural Selection, trad. Matthew Cobb de Darwin et l'Aprés Darwin (Kimé, París, 1994), Cambridge University Press, Cambridge/Nueva York.

Ghiselin, Michael T., 1975, “The Rationale of Pangenesis", Genetics, vol. 79, pp.4757.

Glacken, Clarence J., 1967, Traces on the Rhodian Shore: Nature and Culture in Western Thought from Ancient Times to the End of the Eighteenth Century, University of California, Berkeley.

Guyenot, Emile, 1957, Les Sciences de la Vie au XVII et XVIII siècles, Albin Michel, París.

Haller, Albert, 1772, La Génération ou exposition des phénomènes relatives à cette fonction naturelle, Chez de la Dove, París, 2 vols.

Haller, Albert v., 1752, Reflexions sur le Système de la Génération de M. de Buffon, Barrilot et Fils, Ginebra (traducción del prefacio del vol. 2 de la primera edición alemana de la OEuvre de Buffon), París. Versión en inglés de P.S. Sloan: "Reflections on the Theory of Generation of Mr. Buffon", Lyon \& Sloan (eds.), 1981.

Hannaway, Caroline, 1993, "Environment and Miasmata" en Bynum y Porter, 1993, pp. 292-307.

Harvey, William, 1651 (1981), Disputations Touching The Generation of Animals, Blackwell Scientific Publications, Oxford.

Héritier-Augé, Françoise, 1985, "Le Sperme el le sang, de quelques théories anciennes sur leur genèse et leurs rapports", Nouvelle Revue de Psychanalyse, vol. 32, pp. 111-122 [versión en inglés: "Semen and Blood: Some Ancient Theories Concerning their Genesis and Relationship", en M. Feher (comp.), 1989, Zone: Fragments for a History of the Human Body, parte 3, The MIT Press, Nueva York, pp. 159-175]. 
Hilts, Victor, 1984, "Enlightenment Views on the Genetic Perfectibility of Man", en Everett Mendelsohn (ed.), Transformation and Tradition in the Sciences, Cambridge University Press, Cambridge, U.K.

Hipócrates, 1923a, "Airs, Waters, Places", en Works, Heinemann, Loeb Classical Library, Londres.

_, 1923b, “The Nature of Man”, en Works, Heinemann, Loeb Classical Library, Londres.

Hoffheimer, M.H., 1982, "Maupertuis and the $18^{\text {th }}$-Century Critique of Preexistence", Journal of the History of Biology, vol. 15, no. 1 (primavera), pp. 119-144.

Hunter, John, 1861, Essays and Observations on Natural History, ed. R. Owen, Londres, 2 vols.

- 1786, Observations on Certain Parts of the Animal Oeconomy, Castle Street, Londres.

Huxley, Thomas H., 1878, "Evolution in Biology", en Darwiniana; Essays, 1896, Appleton, Nueva York.

Jacob, François, 1970, La Logique du vivant, une histoire de l'hérédité, Gallimard, París.

Jarcho, Saul, 1970, "Galen's Six Non-Naturals", Bulletin of the History of Medicine, vol. 44, pp. 372-377.

Kant, Immanuel, 1775 (1997), "On the Different Races of Man”, en Chukwudi, 1997, pp. 38-48.

Lloyd, G.E.R., 1983, Science, Folklore and Ideology, Studies in the Life Sciences of Ancient Greece, Cambridge University Press, Cambridge.

Lindeboom, G.A., 1970, "Boerhaave's Concept of the Basic Structure of the Body", Clio Medica, vol. 5, pp. 203-208.

Lonie, Ian M., 1981, The Hippocratic Treatises, traducción y comentarios de "On Generation", "On the Nature of the Child" y "Diseases IV", Walter Gruyter, Berlín/Nueva York.

López-Beltrán, Carlos, 2000, "Por una crítica de la noción de RAZA", Ciencias, UNAM, no. 60-61, enero.

—_ 1997, "Perfectionner le corps: des défauts héréditaires à l'hérédité fatale", trabajo presentado en la reunión l'Eugénisme, 1945 et après, Universidad de Dijon, Francia, septiembre de 1997. Aparecerá en Jean Gayon y Daniel Jacobi (eds.), en prensa.

— 1995 , “Les maladies héréditaires'. $18^{\text {th }}$-Century Disputes in France”, Revue d'Histoire des Sciences, vol. XLVIII, no. 3, pp. 307-350.

—, 1994 , "Forging Heredity, from Metaphor to Cause: A Reification Story", en Studies in the History and Philosophy of Science, vol. 25, no. 2, pp. 211-235.

López-Beltrán, Carlos, 1992, Human Heredity 1750-1870. The Construction of a Domain, tesis doctoral, King's College, Londres.

Louis, Antoine, 1749, Dissertation envoyée á l'Academie des Sciences de Dijon, pour le prix de l'année 1748, sur la question... Comment se fait la transmission des maladies héréditaires?, Delaguete, 12o, París.

Lyon, John y P.R. Sloan (comps.), 1981, From Natural History to the History of Nature. Readings from Buffon and his Critics, University of Notre Dame Press, Notre Dame.

Maupertuis, P.L.M., 1745, Vénus physique, La Haya. 
Maupertuis, P.L.M., 1744, Dissertation physique à l'occasion du Nègre Blanche, Leyde, París.

Mazzolini, Renato G. y Shirley A. Roe, 1986, Science against the Unbelievers: The Correspondence of Bonnet and Needham, 1760-1780, Voltaire Foundation at the Taylor Institution (Studies on Voltaire and the Eighteenth Century, 243), Oxford.

McLaughlin, Peter, 2000, "Preliminary Notes on Biological Notions of Heredity in the Enlightenment", presentadas en el encuentro sobre Cultural History of Heredity, Max Planck Institute for the History of Science, mayo.

Miller, Genevieve, 1962, “Airs, Waters and Places' in History”, en Journal of the History of Medicine, vol. 17, pp. 129-140.

Morsink, J., 1979, “Was Aristotle's Biology Sexist?”, Journal of the History of Biology, vol. 12 (primavera), pp. 83-112.

Niebyl, P.H., 1971, "The Non-Naturals", Bulletin of the History of Medicine, vol. 45, pp. 486-492.

Nutton, Vivian, 1993, "Humoralism”, en Bynum y Porter 1993, vol. 1, pp. 281-290.

Odom, Herbert, 1970, Groundwork for Darwin, Theories of Heredity and Variation, Great Britain 1790-1820, tesis doctoral, Harvard, Cambridge, Mass.

Pagès, Jean-François, 1798, "Héréditaires (maladies)", en Dictionnaire de Médecine, parte de la Encyclopedie Methodique, vol. VII, an VI de la République, chez Agasse, pp. 160-176.

Portal, Antoine, 1808, Considerations sur la nature et le traitement de quelques maladies héréditaires, ou de famille, Mem. Inst. Nat. de France, t. 8, Semestre 2, p. 156. Leído en el Instituto el 25 de enero de 1808 y publicado posteriormente como libro en 1808, París, 4o., y en una versión revisada y ampliada en 1814; 3a. ed., París. Se publicaron extractos de esta obra en Graperon, Bull. des Sci. Méd., tomo 2, p. 328.

Porter, Roy, 1995, "Medical Science and Human Science in the Enlightenment", en Fox, C., R. Porter y R. Wolkler (comps.), 1995, Inventing Human Science, University of California Press, pp. 53-87.

Preus, A., 1975, Science and Philosophy in Aristotle's Biological Works, Olms, Nueva York.

Prichard, James Cowles, 1833, “Temperament”, en Cyclopedia of Practical Medecine, vol. 4, pp. 159-174.

— 1813 , Researches into the Physical History of Man, J. \& A. Arch, Londres (basada en su tesis de 1808, De generis humani varietate, Abernethy \& Walker, Edimburgo; edición facsimilar de G.W. Stocking: Chicago University Press, 1973).

— 1826, Researches into the Physical History of Mankind, 2a. ed. revisada y aumentada, J. \& A. Arch, Londres, 2 vols.

Pujol, Alexis, 1802, "Essai sur les Maladies Héréditaires", ensayo escrito para la Royal Society of Medicine para el concurso de 1788-1790, en CEuvres Médicales, Castres, 4 vols., en 8o.; 2a. ed., Oeuvres de Médecine Practique, F.G. Boisseau (ed.), con notas, una biografía y adiciones, 2 vols., Bailliere \& Bechet, París, 1823.

Rádl, Emanuel, 1930, The History of Biological Theories, trad. E.J. Hatfield, Oxford University Press (especialmente el capítulo XXII, "Human Heredity") [versión en castellano: Historia de las teorías biológicas, trad. F. Díez Mateo y F. García del Cid, Revista de Occidente, Madrid, 1931]. 
Rather, L.-J., 1968, "The Six Things Non-Naturals: A Note on the Origins and Fate of a Doctrine and Phrase", Clio Medica, vol. 3, pp. 337-347.

Rey, Roselyne, 2000, Naissance et développement du vitalisme en France de la deuxième moitiè du XVIII siecle a la fin du Premier Empire, Voltaire Foundation, Oxford.

—_, 1989, "Génération et Hérédité au XVIII ${ }^{\mathrm{e}}$ siècle”, en Bénichou 1989, pp. 7-48.

Richards, Robert J., 1992, The Meaning of Evolution. The Morphological Construction and Ideological Reconstruction of Darwin's Theory, The University of Chicago Press, Chicago.

Ritvo, Harriet, 1997, The Platypus and the Mermaid, and Other Figments of the Classifying Imagination, Harvard University Press, Boston.

Robinson, Gloria, 1979, A Prelude to Genetics, Theories of a Material Substance of Heredity: Darwin to Weismann, Coronado Press, Lawrence, Kansas.

Roe, Shirley, 1981a, Matter, Life and Generation, XVIII ${ }^{\text {th }}$ Century Embriology and the Haller-Wolff Debate, Cambridge University Press, Cambridge, UK.

— (ed.), 1981b, The Natural Philosophy of Albert von Haller, Arno Press, Nueva York.

Roger, Jacques, 1963, Les Sciences de la vie dans la pensée française du XVIII siècle, Armand Colin, París.

— 1989, Buffon, un Philosophe au Jardin de Roi, Fayard, París.

Russell, Nicholas, 1986, Like Engend'ring Like, Heredity and Animal Breeding in Early Modern England, Cambridge University Press, Cambridge, UK.

Schiller, J., 1978, La Notion d'organisation dans l'Histoire de la Biologie, Maloin, París.

— 1974 , "Queries, Answers and Unsolved Problems in $18^{\text {th }}$ Century Biology", History of Science, vol. 12, pp. 191-192.

Schopfer, W.H., 1946, "L'Histoire des theories relatives a la generation aux $18^{\mathrm{eme}}$ et $19^{\text {eme }}$ siecles", Gesnerus. Swiss Journal of the History of Medicine and Sciences.

Sharples, R.W., 1985, "Species, Form and Inheritance: Aristotle and after", en Allan Gotthelf (ed.), Aristotle on Nature and Living Things, Bristol Classical Press, Brístol, 1985, pp. 117-128.

Staum, Martin S., 1980, Cabanis - Enlightenment and Medical Philosophy in the French Revolution, Princeton University Press, Princeton.

Williams, Elizabeth Ann, 1994, The Physical and the Moral: Anthropology, Physiology, and Philosophical Medicine in France, 1750-1850, Cambridge University Press, Cambridge.

Zirkle, Conway, 1951, "The Knowledge of Heredity before 1900", en L.C. Dunn (ed.), Genetics in the 20th Centuy. Essays on the Progress of Genetics during its First 50 years, Macmillan, Nueva York.

,- 1946 , "The Early History of the Idea of the Inheritance of Acquired Characters and of Pangenesis", en Transactions of the American Philosophical Society, vol. 38, pp. 91-151.

Recibido: 13 de diciembre de 2001; aceptado: 19 de marzo de 2002 